\title{
Caja de herramientas para la gestión de centros históricos
}

\author{
Erika Argentina Zambrano Irías
}

\section{Resumen}

En Honduras se han iniciado procesos de recuperación de centros históricos como una acción de la gestión urbana, con el fin de proteger el patrimonio cultural del país, entre las acciones identificadas se encuentra la documentación del patrimonio. Documentar el patrimonio requiere de criterios y metodologías que orienten la recolección de información y faciliten su posterior recuperación, por lo que se plantea la necesidad de identificar instrumentos que orienten estos procesos de gestión territorial.

El uso de la tecnología como el software especializado en datos cartográficos, es de gran utilidad en este tema; hoy en día los Sistemas de Información Geográfica (SIG) se han convertido en una potente herramienta para el análisis socio-espacial y la planificación territorial. Como un aporte sustancial de la investigación de tesis: "Los sistemas de información geográfica como una herramienta tecnológica para la gestión del patrimonio", se ha generado conceptual y metodológicamente a partir de criterios técnicos, una Caja de Herramientas para la Gestión de Centros Históricos, con el fin de dar soporte tecnológico al proceso de gestión del patrimonio.

Se presentan los instrumentos necesarios para la construcción de sistemas de información geográfica, concebidos como herramienta de apoyo en la gestión del territorio, en este caso los centros históricos hondureños.

Palabras clave: SIG. Herramientas SIG. Gestión de centros históricos.

\section{Abstract}

In Honduras as an action of urban management Historical Centers have initiated recovery processes, as goal to protect cultural patrimony. Among the identified actions in these processes, is the patrimony documentation. In order to facilitate later retrieval, several criteria and methodologies are required in the gathering of information. So that there is a need to identify instruments that guide these processes territorial management.

Technologies as well as specialized software in cartographic data are very useful in this area. Now days the systems of geographic information are a strong tool for the analysis socio - spatial and the territorial planning. As a substantial contribution of 
the thesis investigation "The geographic information system as a technological tool for the patrimony management", has been generated conceptually and a methodologically since technical criteria, a box of tools for the historical centers management to provide technological support to the process patrimony management.

We present the necessary tools for building geographic information systems, designed as a support tool in the management of the territory, in this case historical centers Hondurans.

Keywords: GIS. Tools GIS. Management of historical centers.

Erika Argentina Zambrano Irías (erikazambranoi@yahoo.com). Universidad Nacional Autónoma de Honduras, Facultad de Ciencias Sociales, Maestría en Gestión Social Urbana. Centro Nacional Suizo de Competencia en Investigación Norte - Sur (NCCR North - South). 


\section{INTRODUCCIÓN}

La participación con esta comunicación parte del producto central de la tesis: "Los sistemas de información geográfica como una herramienta tecnológica en la gestión de centros históricos en Honduras".

Se logran identificar una serie de herramientas básicas que en su conjunto facilitan el proceso de gestión de centros históricos, pero que a su vez la versatilidad, flexibilidad y tendencias en el desarrollo tecnológico permite incorporar otros instrumentos conforme a la necesidad de cada territorio. Esta identificación y aplicación de herramientas nos permite validar la potencialidad de los SIG.

Presentamos la metodología utilizada para la concepción de la caja de herramientas, las orientaciones teóricas que nos permiten desarrollar el tema, los instrumentos que componen la caja de herramientas y las conclusiones preliminares de este estudio.

La caja de herramientas está compuesta por cinco herramientas básicas, estas a su vez (en algunos casos) disponen de instrumentos que se presentan y son descritos brevemente en este documento: 1) Flujograma de información para la gestión territorial del patrimonio cultural 2) Instrumentos para la delimitación del centro histórico 3) Inventario de bienes inmuebles de la República de Honduras 4) Software SIG y 5) Datos cartográficos.

\section{APUNTES METODOLÓGICOS}

Esta propuesta se realiza con el fin de proporcionar las herramientas que faciliten el vínculo entre dos áreas del conocimiento: la gestión del patrimonio cultural, particularmente los centros históricos y los SIG

Para la construcción de esta caja de herramientas, metodológicamente partimos de la definición de SIG y sus componentes, así como de los procesos de gestión del patrimonio cultural, específicamente el patrimonio tangible en el cual están catalogados los centros históricos.

El objeto de aplicación de esta comunicación son los centros históricos y considerando que este tema es solo una parte de una investigación más extensa, es pertinente explicitar que el primer instrumento que ofrece la caja de herramientas es un flujograma de información y recursos disponibles para la gestión territorial del patrimonio cultural. 
Los instrumentos que componen la caja de herramientas son producto de los procesos obtenidos en el flujograma de información y se describen conforme a los componentes de un SIG; los datos, el software, el hardware, los métodos y el recurso humano.

Inicialmente se realiza la búsqueda e identificación de instrumentos disponibles; elementos jurídicos, normativos y manuales de gestión de los centros históricos hondureños.

Paralelamente se definieron los elementos (instrumentos) de la caja de herramientas, que son clasificados temáticamente a partir de los componentes de un SIG, se determinó una escala de prioridades teniendo como punto de partida las deficiencias, vacios y el desaprovechamiento de recursos. Los datos, el software y los métodos fueron los elementos seleccionados para ser desarrollados con mayor precisión. Definidos los componentes principales se determinan los instrumentos específicos.

Finalmente se diseña una propuesta conceptual y metodológica de la caja de herramientas para SIG de centros históricos, presentando los elementos disponibles, su utilización y el proceso de construcción de capas temáticas que facilitaran la gestión de centros históricos a partir de recursos disponibles. Se ha hecho uso de Google Earth y del software Quantum GIS versión 1.8.0 Lisboa para la presentación de imágenes.

El proceso de esta investigación presenta las herramientas que a partir de una planificación sistemática, facilitan los procesos de gestión territorial como es el caso los de los centros históricos hondureños.

\section{MARCO CONCEPTUAL}

En esta sección presentamos los conceptos centrales que giran alrededor de esta comunicación, los centros históricos como contexto de aplicabilidad y los SIG como herramienta tecnológica para la gestión de este territorio.

\subsection{Centros Históricos}

Toda ciudad posee un núcleo original, que en la actualidad y para las futuras generaciones conserva la historia de sus antepasados, posee un valor patrimonial, y en la mayoría de los casos, son espacios donde se han establecido las principales actividades político-administrativas y económicas de nuestras ciudades. 
En la recomendación de la UNESCO (1976) relativa a la salvaguardia de los conjuntos históricos y su función en la vida contemporánea, los centros históricos:

"Se considera conjunto histórico o tradicional todo grupo de construcciones, y de espacios, inclusive los lugares arqueológicos y paleontológicos, que constituyan un asentamiento humano tanto en medio urbano como en medio rural y cuya cohesión y valor son reconocidos desde el punto de vista arqueológico, arquitectónico, prehistórico, histórico, estético o sociocultural. Entre esos 'conjuntos', que son muy variados, pueden distinguirse en especial: los lugares prehistóricos, las ciudades históricas, los antiguos barrios urbanos, las aldeas y los caseríos, así como los conjuntos monumentales homogéneos, quedando entendido que estos últimos deberán por lo común ser conservados cuidadosamente sin alteración" (UNESCO, 1976, p. 142).

Se define la gestión de centros históricos como el conjunto de actuaciones destinadas a hacer efectivo el conocimiento, conservación y difusión de los bienes patrimoniales, lo que incluye ordenar y facilitar las intervenciones (físicas y culturales) que en el centro histórico se realice. (Abejón y Maldonado, 2006, p. 15).

Los conceptos de gestión del patrimonio y la definición particular de gestión de centros históricos, nos permite identificar tres acciones en el proceso de gestión del patrimonio cultural, que a su vez corresponden a la propia gestión de centros históricos: la planificación, el control y la difusión. Estas acciones deben ser desarrolladas conjuntamente (Ver Figura 1).

Figura 1: Procesos de gestión

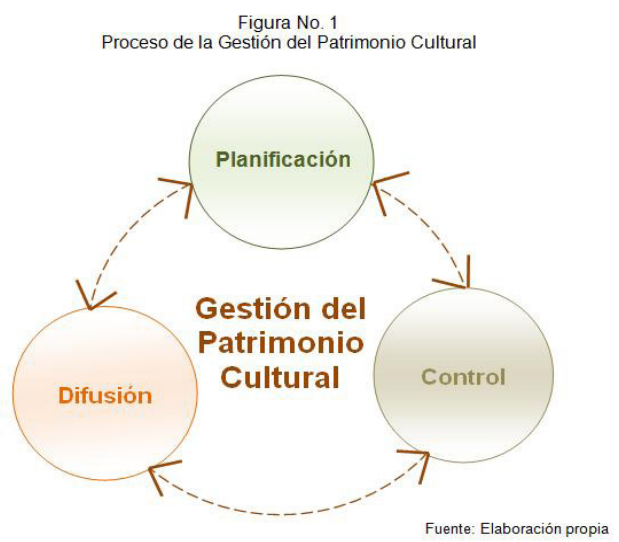

Fuente: Elaboración propia. 
La planificación es una actividad articuladora en el proceso de gestión, comprendiendo por planificar, la organización o estructuración de actividades, en un tiempo determinado, asignación de responsables y recursos necesarios para el logro de fines establecidos. La ejecución y la no ejecución de estas actividades, que normalmente se presentan a través de planes, programas y proyectos, deben ser vigiladas a través de la acción de Control con el fin de promover la toma de decisiones correctoras y preventivas. Finalmente es preciso Difundir a la sociedad (las comunidades) con el fin de dar a conocer los valores y bienes que se poseen, de tal manera que logren valorarlos, protegerlos y sobre todo disfrutarlos.

En Honduras el ente responsable de la gestión de los espacios geográficos denominados centros históricos es el Instituto Hondureño de Antropología e Historia $(\mathrm{HAH})$, creado con el nombre de Instituto Nacional de Antropología e Historia mediante el Decreto No. 245 del 22 de julio de 1952, sin embargo "el proceso de delimitación y declaratoria de centros urbanos con valor histórico, antropológico y arquitectónico, comienza en el año de 1972 con la declaratoria del Centro Histórico de Comayagua" (AMHON-PGU, 2012, p. 10).

Esta en vigencia la Ley para la Protección del Patrimonio Cultural (PPC), Decreto 220-97, que constituye el marco legal en lo concerniente a la protección y conservación del Patrimonio Cultural de la Nación, el Estado a través de esta ley faculta al IHAH para ello. Actualmente Honduras cuenta con 14 centros históricos declarados (Ver Mapa 1) y 15 en proceso de declaratoria.

\section{Mapa 1: Centros Históricos Hondureños con declaratoria} mediante Decreto - Marzo 1013

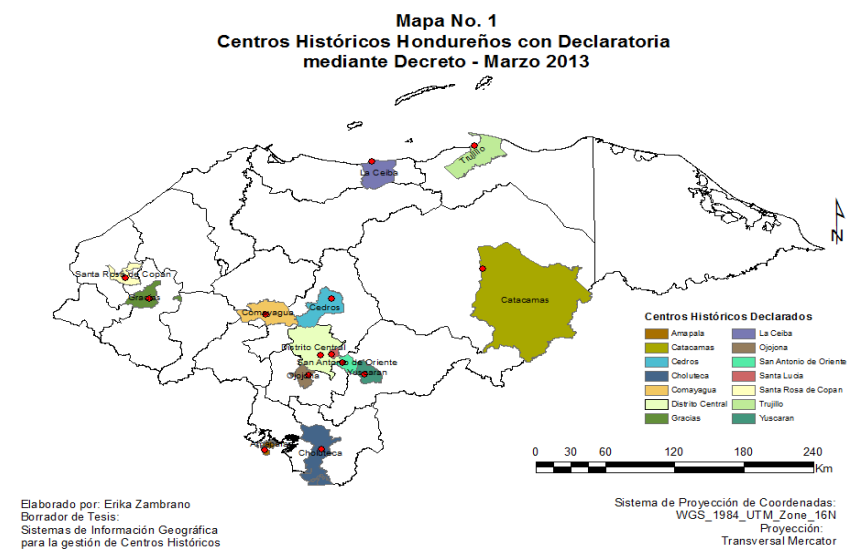




\subsection{Sistemas de información geográfica}

La relevancia de los Sistemas de Información Geográfica (SIG) conocido también por sus siglas en inglés Geographic Information System (GIS), es la utilidad que estos brindan a la gestión, planificación y ordenación del territorio.

Distintos autores han conceptualizado los SIG, algunos de ellos acentúan su componente de base de datos, otros sus funcionalidades y otros enfatizan el hecho de ser una herramienta de apoyo en la toma de decisiones, pero todos coinciden en referirse a un SIG como un sistema integrado para trabajar con información espacial, herramienta esencial para el análisis y toma de decisiones. A partir de la identificación de los elementos esenciales de una discusión teórica hemos definido los "SIG como un sistema compuesto de hardware, software, recursos humanos, datos y métodos para la captura, relación, análisis, actualización y representación territorial de un espacio físico determinado" (Ver Figura 2).

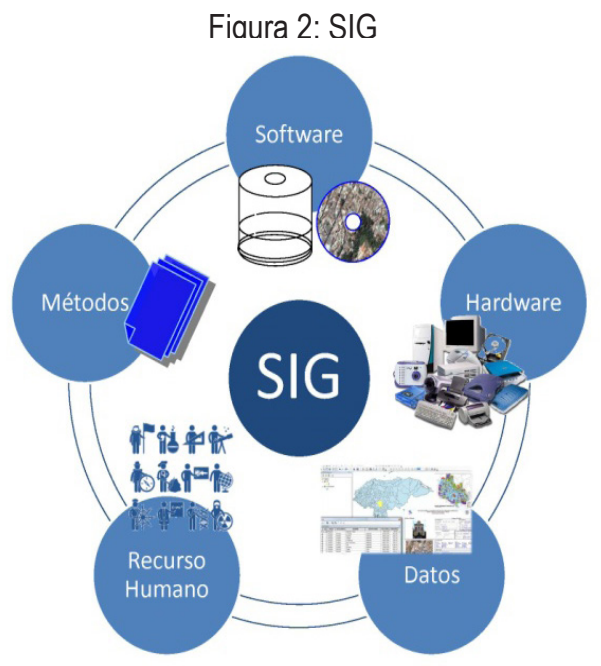

Fuente: Elaboración propia.

Describimos brevemente los elementos que componen los SIG, los instrumentos o herramientas que componen la caja son clasificados a partir de estos.

Software (SF): Esta definido como un conjunto de programas, instruccio- 
nes y reglas informáticas para ejecutar ciertas tareas en una computadora ${ }^{1}$. El SF SIG, es el encargado de realizar las operaciones y manipulación de los datos tanto geográficos como cuantitativos y cualitativos mediante el uso de bases de datos. Estos permiten visualizar datos geográficos y alfanuméricos en forma conjunta e integrada, administrar la información geográfica por capas y en distintos tipos y formatos, y desarrollar análisis espaciales sobre dichos conjuntos de datos con el fin de obtener nueva información (Piumetto, 2007).

Hardware $^{2}(\mathrm{HW})$ : Es definido como el conjunto de los componentes físicos que integran un sistema de cómputo. Cuando nos referimos a hardware, hablamos de alguna plataforma de computador, son factibles el uso de modestos ordenadores personales los que conocemos como PC o potentes estaciones de trabajo. Para el desarrollo de SIG son de suma importancia otros dispositivos como las tablas digitalizadoras, escáneres, plotters o impresoras de carriles anchos, GPS, entre otros.

Datos: De acuerdo a la Real Academia Española, dato es: antecedente necesario para llegar al conocimiento exacto de algo o para deducir las consecuencias legítimas de un hecho. El dato o los datos por sí solos no tienen significado, pero son importantes ya que son la base para la creación de información, toman importancia cuando añadimos algún tipo de valor. Es decir, un número que no esté acompañado de un sustantivo, un adjetivo o un calificativo no nos proporciona información más que un número.

Los datos que utilizamos en un SIG son de tipo, espaciales y temáticos. Los datos espaciales pueden representarse a través de modelos; raster y vectorial, mientras que los datos temáticos pueden estar determinados por información cuantitativa o cualitativa, generalmente estructurados en bases de datos o tablas.

Métodos: Se entiende por método una ruta que nos lleva a un destino, pasos o procedimientos a seguir para la obtención de un fin. Para la construcción de un SIG es indispensable una clara definición de objetivos y tareas, esto permitirá la optimización de datos y recursos tecnológicos así como la correcta selección de los demás componentes de un SIG. El uso de esos recursos será más eficiente.

Recursos humanos: De acuerdo con Chiavento (2001), los recursos huma-

\footnotetext{
${ }^{1}$ Una palabra del vocabulario inglés pero que ya ha sido aceptada por la Real Academia Española, la definición es tomada del Diccionario de la RAE.

2 lbid.
} 
nos son personas que ingresan, permanecen y participan en una organización, en cualquier nivel jerárquico, realizando cualquier tarea. En cuanto al recurso humano SIG quizás sea el componente más complejo, la conformación de equipos, la capacitación y actualización permanente de estos, la especialización en las diferentes áreas de implicación en los SIG, significan una alta inversión en cuanto recurso tiempo y costo económico. Los SIG son herramientas utilizadas en diferentes disciplinas por lo tanto han dejado de ser un campo de y para expertos del sector.

\section{CAJA DE HERRAMIENTAS PARA LA GESTIÓN DE CENTROS HISTÓRICOS}

Entenderemos por caja de herramientas; el conjunto de instrumentos 0 herramientas que facilitan la construcción de un determinado bien, a partir de esta definición de construcción propia y para efectos de esta investigación; una caja de herramientas SIG consistirá en el conjunto de instrumentos o herramientas básicas que facilitaran la construcción de un sistema de información geográfica para centros históricos, investigaciones posteriores podrán nutrir esta herramienta con nuevos elementos (Ver Figura 3).

Como se presenta en el referente teórico, los componentes de un SIG son: los datos, el software, el hardware, el recurso humano y los métodos. Los datos y el software, pueden representar la mayor inversión de recursos (tiempo y dinero) en proyectos SIG, en ese sentido, la caja de herramientas se abre a la posibilidad de estar compuesta por instrumentos o herramientas existentes, como por ejemplo el Inventario Nacional de Bienes Inmuebles elaborado por el IHAH y las municipalidades, una fuente primaria de datos y la promoción del uso de software libre.

Figura 3: Contenido de la caja de herramientas

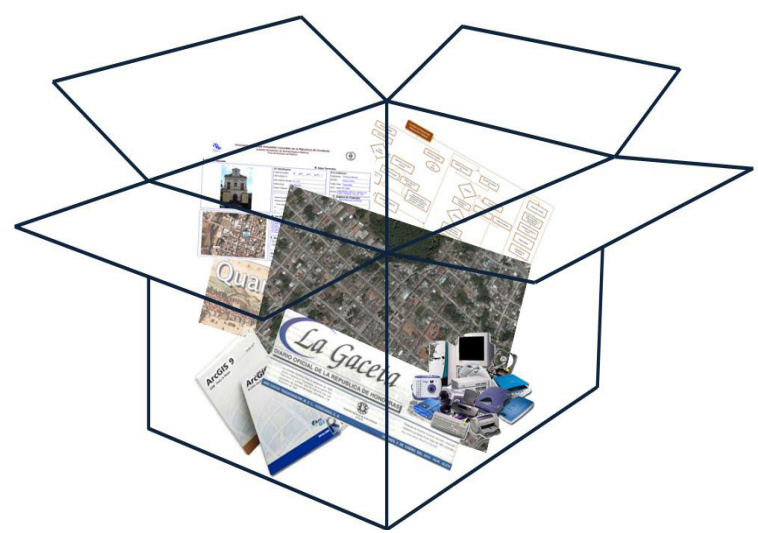

Fuente: Elaboración propia. 
A continuación describimos cada una de las herramientas que componen la caja que facilitarán la construcción de SIG para la gestión de los centros históricos hondureños:

4.1 Herramienta № 1: Flujograma de información para la gestión territorial del patrimonio cultural

Tal como su nombre lo indica se presenta un flujograma que determina los pasos o procesos a seguir para la construcción de un SIG y facilitar con este la gestión territorial del patrimonio, particularmente los centros históricos (Ver Figura 4). 


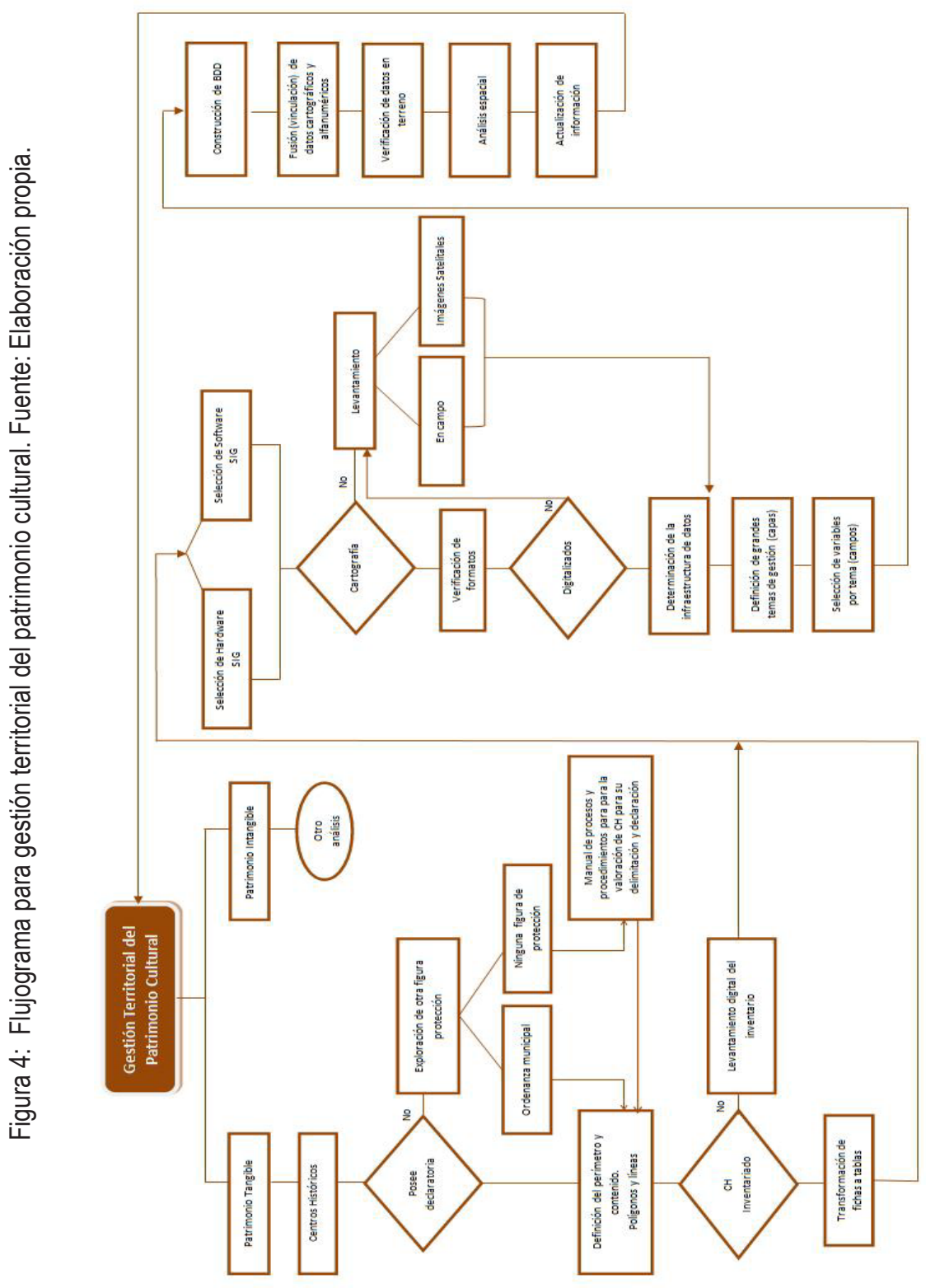




\subsection{Herramienta $\mathrm{N}^{0}$ 2: Instrumentos para la delimitación de centros históricos}

De acuerdo con el vocabulario de Gestión del Patrimonio Cultural y del Turismo Cultural (Abejón y Maldonado s.f.) se define como delimitación del entorno, la fijación precisa del perímetro de protección de un inmueble con el fin de controlar y proteger las relaciones entre dicho inmueble y el entorno que lo rodea.

Se identifican dos figuras legales que permiten delimitar con precisión los centros históricos:

a) Conforme a la legislación hondureña y a los procesos establecidos por el Instituto Hondureño de Antropología e Historia, los centros históricos son declarados mediante decretos legislativos y acuerdos ejecutivos y b) En los sitios donde aun no se logra la declaratoria, es posible la existencia de una ordenanza municipal que especifique los límites geográficos con el fin de proteger el patrimonio.

Estos instrumentos nos permiten construir lo que conocemos como perímetro (polígono) así como los elementos principales de la estructura urbana: calles, avenidas, ríos (líneas) conformación de barrios, manzanas y lotes (polígonos) que conforman este territorio (Ver Figura 5).

Para los sitios que no cuentan con la declaratoria o con una ordenanza municipal, hemos identificado un valioso instrumento: el Manual de Procesos y Procedimientos para Valoración de Centros/Conjuntos Históricos para su Delimitación y Declaratoria, elaborado por la Asociación de Municipios de Honduras (AMHON) a través del Programa de Gestión Urbana en Centros Históricos con el apoyo del IHAH y la Agencia Española de Cooperación Internacional y Desarrollo (AECID). 
Figura 5: Delimitación y estructura urbana de del Centro Histórico de Comayagua

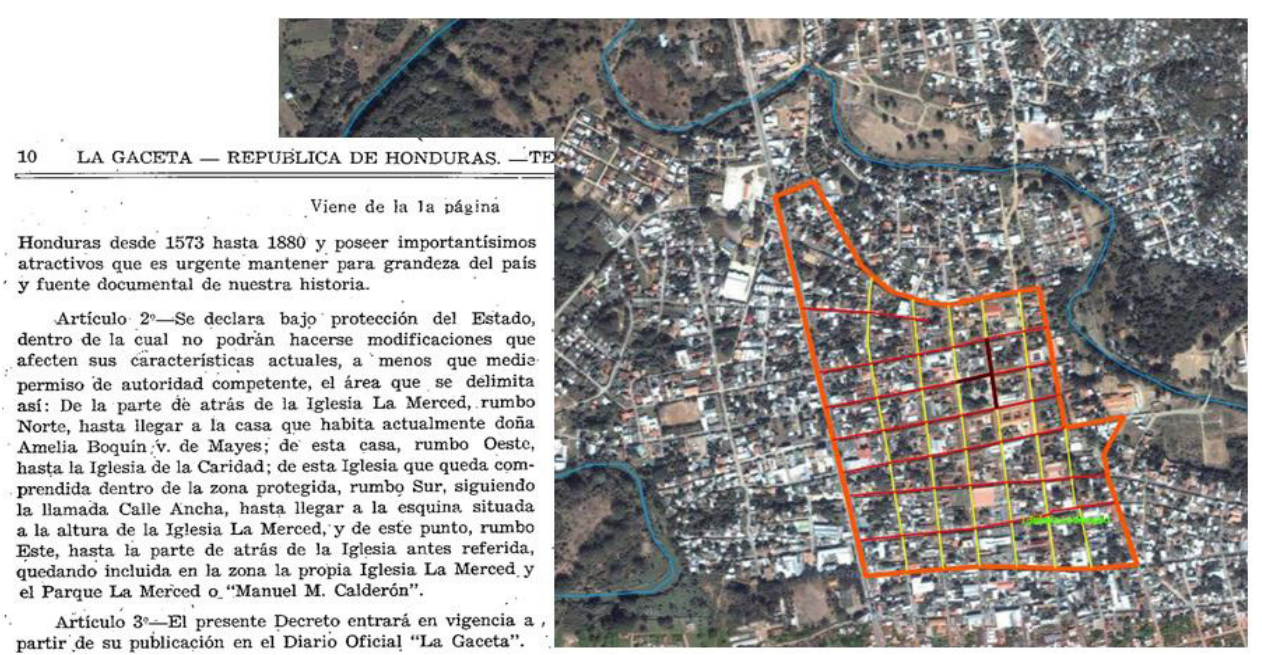

Fuente: Diario Oficial La Gaceta 1972 No. 20,869. Imagen Satelital Google Earth 2013

\subsection{Herramienta $N^{0} 3$ : Inventario de bienes inmuebles de la República de Honduras}

Es deber del IHAH la realización del inventario y registro nacional de los bienes culturales hondureños, en ese sentido esta institución con el apoyo de la cooperación internacional y las municipalidades ha estandarizado una serie de fichas que permiten la recolección de información; la ficha de inventario de edificios, la ficha de inventario de conjuntos históricos, la ficha de inventario de espacios públicos abiertos, entre otras.

La ficha que nos facilita la información para la gestión territorial del patrimonio es la de inventario de edificios, se recogen por lo menos 14 categorías temáticas, entre datos generales, régimen de propiedad, uso de suelo, marco legal, referencia histórica, esquema arquitectónico, datos arquitectónicos, características formales, descripción del inmueble, medidas, servicios, alteraciones tipológicas, patología del edificio y peligros potenciales.

La disponibilidad de esta información nos permitirá estructurar tablas 0 bases de datos que también forman parte de este conjunto de herramientas, se presentan algunas que se consideran prioritarias para la construcción del SIG (Ver Figura 6). 
Figura 6: Estructura de datos

\begin{tabular}{|l|}
\hline \multicolumn{1}{|c|}{ Identificación } \\
\hline Código del Edificio \\
\hline Clave Catastral IP \\
\hline Clave Catastral Municipal \\
\hline Nombre Actual \\
\hline Nombre Tradicional \\
\hline
\end{tabular}

\begin{tabular}{|l|}
\hline \multicolumn{1}{|c|}{ Localización } \\
\hline Departamento \\
\hline Municipio \\
\hline Ciudad/Aldea \\
\hline Barrio/Cascrio \\
\hline Dirección exacta \\
\hline
\end{tabular}

\begin{tabular}{|l|l|}
\hline Régimen de Propiedad & \multicolumn{1}{c|}{ Uso de Suelo } \\
\hline Nombre del Propictario & Tradicional \\
\hline Régimen de Propiedad & \\
\hline Dominio \\
\hline Condición dePredio \\
\hline
\end{tabular}

\begin{tabular}{|l|}
\hline $\begin{array}{l}\text { Caracteristicas del } \\
\text { Inmueble }\end{array}$ \\
\hline Tipo de predio \\
\hline Numero de niveles \\
\hline Linea de construcción \\
\hline Materiales parodes exteriores \\
\hline Estado paredes exteriores \\
\hline Materiales paredes interiores \\
\hline Estado paredes interiores \\
\hline Tipo de techo \\
\hline Material de techo \\
\hline .... \\
\hline
\end{tabular}

\begin{tabular}{|l|}
\hline $\begin{array}{l}\text { Alteraciones } \\
\text { Tipologicas }\end{array}$ \\
\hline Subdivisiondel predio \\
\hline Modificaciones \\
\hline $\begin{array}{l}\text { Eliminación de elementos } \\
\text { estucturales }\end{array}$ \\
\hline Nuevoselementos \\
\hline \\
\hline
\end{tabular}

\begin{tabular}{|l|l|}
\hline Peligros potenciales & Patologia del Edificio \\
\hline Danerales \\
\hline Riesgos Extenos \\
\hline Otros riesgos \\
\hline Exposición a Desastres \\
\hline \multicolumn{1}{|c|}{ Cansas } \\
\hline \\
Fuente: Elaboración propia
\end{tabular}

\subsection{Herramienta N ${ }^{\circ}$ 4: Software SIG}

Existen en el mercado una serie de distintos paquetes de SIG, todos ellos realizan ciertas operaciones en común, pero cada uno presenta aspectos particulares en cuanto al modelo de datos espaciales que utiliza, operaciones que puede efectuar y cómo las realiza, la manera de almacenar los datos en la base de datos, capacidad y procesamiento de datos y otros (Gómez, Barredo 2005).

El Cuadro 1 nos muestra una descripción de algunos de los software SIG más reconocidos en nuestro contexto, tipo de licencia, principales productos, sus desarrolladores y el link de las páginas web para mayor exploración. 


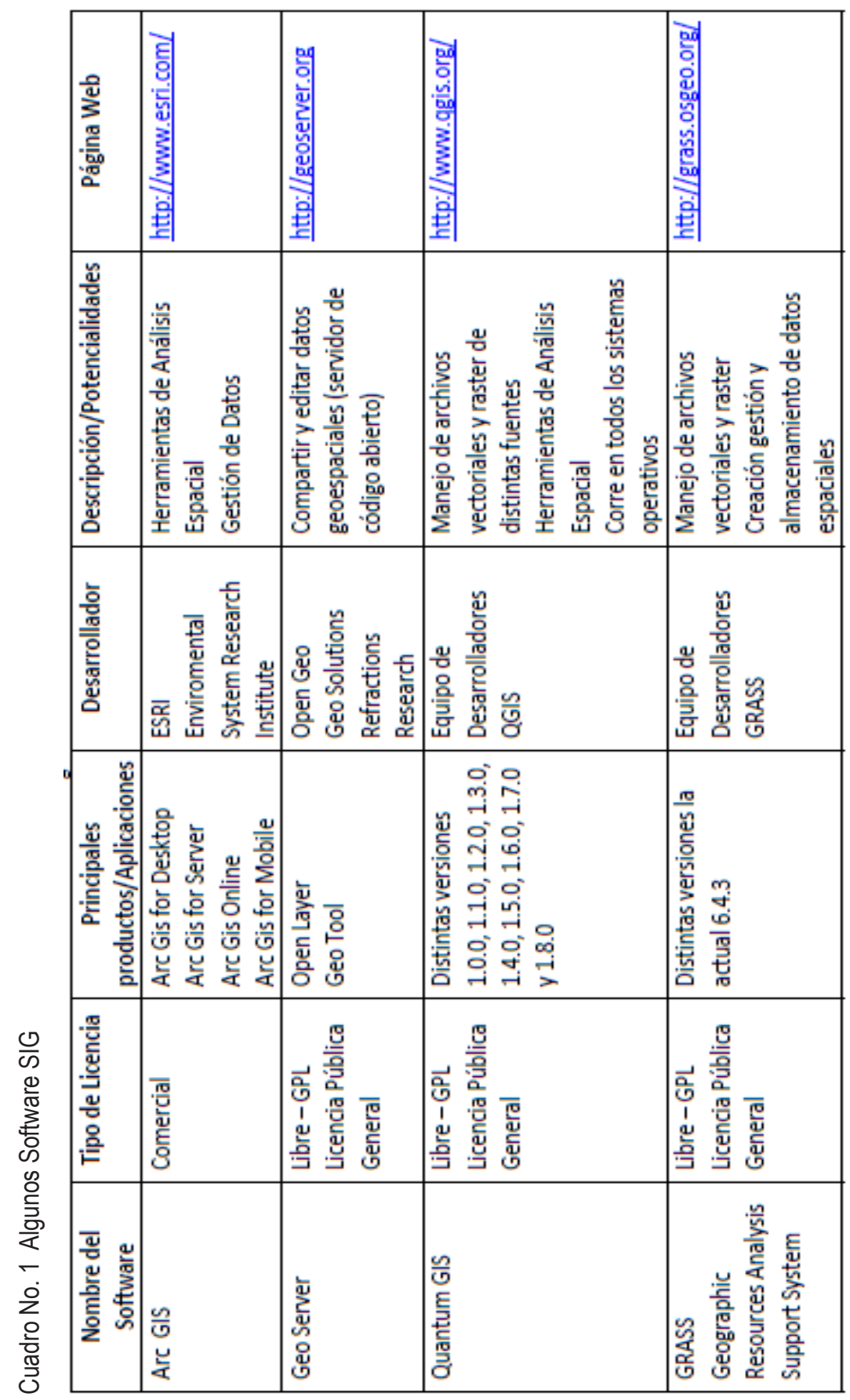




\subsection{Herramienta $\mathrm{N}^{0} 5$ : Datos cartográficos, recursos disponibles de acceso gratuito}

Los catorce centros históricos declarados en Honduras disponen de levantamientos cartográficos, entre dibujos $C A D$, planos sin digitalizar y en algunos casos disponen de información cartográfica en formatos para SIG. La herramienta que aquí se presenta, facilita la digitalización (archivos shapefile), sobre todo para los sitios en los que la información aun no es digitalizada y para los centros históricos por declararse, Google Earth (GE).

Google Earth es un sistema informático basado en la tecnología de sistemas de información geográfica, su función principal y de uso común es visualización imágenes satelitales y mapas del globo terráqueo. La versión básica de GE es gratuita, dispone de otras versiones que tienen un costo y cuentan con características más especializadas entre ellas la resolución de las imágenes, Google Plus, Pro y Enterprice.

En la imagen No. 3 se muestra la disponibilidad de imágenes de centros históricos hondureños (de los catorce se dispone de doce con claridad en la imagen), todas tomadas de la versión básica. El sistema de coordenadas utilizado por GE es el WGS84, muy común en la cartografía hondureña lo que facilita de georeferenciación de las imágenes. 
Figura 7: Disponibilidad de imágenes satelitales en GE
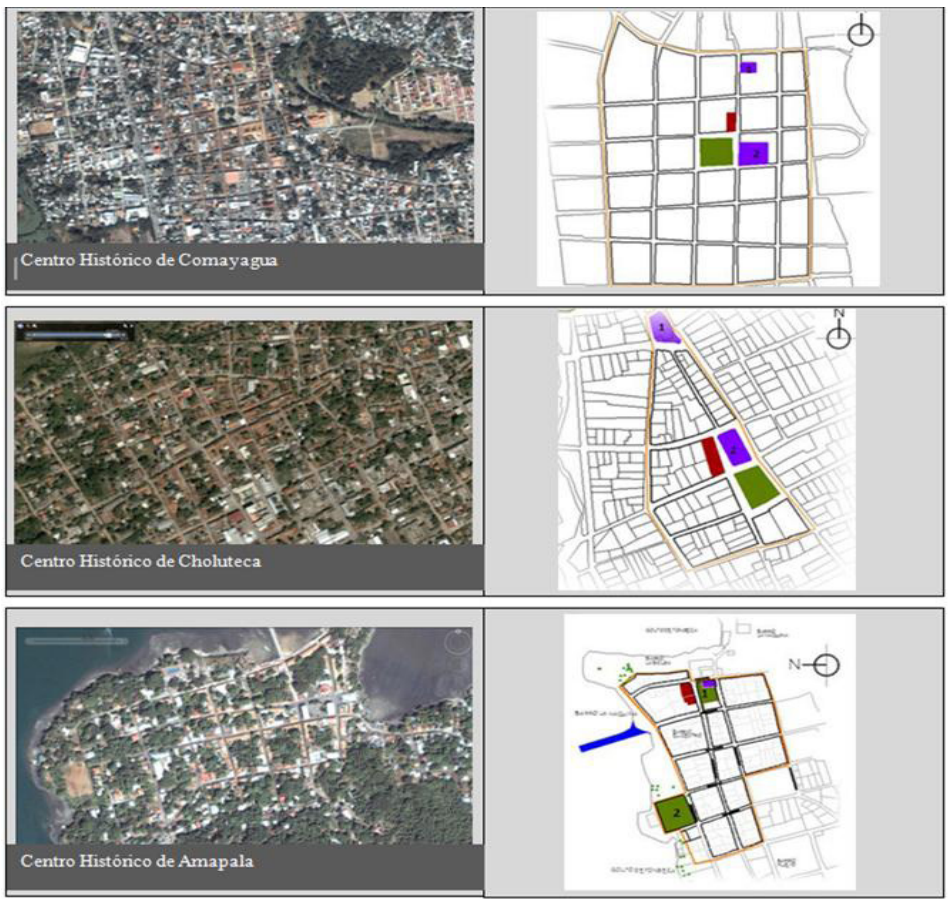

Fuente: Imágenes Google Earth y trabajos de la clase de Urbanismo de la Universidad Católica de Honduras (II período 2011)

\section{CONCLUSIONES}

Se dispone de un marco jurídico, instrumentos legales, producción de instrumentos institucionales; como las metodologías e inventarios realizados por el IHAH con el apoyo de diferentes instituciones y organizaciones, instrumentación que debe ser explotada para la extracción de datos que faciliten la gestión de los centros históricos y conforme a esta propuesta diseñar herramientas tecnológicas como los SIG, considerados una potente herramienta en la planificación territorial.

Los software SIG comerciales siguen presentando limitaciones en cuanto a adquisición por sus altos costos, hoy en día la disponibilidad de software gratis así como del internet, facilita el acceso y el conocimiento de estos paquetes. Las imágenes satelitales que nos ofrece el Google Earth básico, nos permiten contar con una cartografía base de mucha utilidad. 
La caja de herramientas que hemos presentado, facilita la construcción de SIG para centros históricos, indistintamente de la tipología de estos, así como la posibilidad de utilizar los instrumentos y herramientas ya disponibles con el fin de evitar la duplicidad de esfuerzos, reducción en los costos, tiempos y promover la especialización del recurso humano.

\section{BIBLIOGRAFÍA}

- Abejon, Teresa y Maldonado, Ángeles (2006). "El vocabulario de gestión del turismo y del patrimonio cultural" CINDOC del Consejo Superior de Investigaciones Científicas. Disponible en: http://www.gestioncultural.org/recursos_culturales.php?id_enlaces $=140763$

- Asociación de Municipios de Honduras, Programa de Gestión Urbana de Centros Históricos (2012). Manual de procesos y procedimientos para la valoración de centros/conjuntos históricos para su delimitación y declaratoria. Tegucigalpa: Gráficos Tegucigalpa.

- Chiavenato, Idalberto (2001). Administración de recursos humanos, McGrawHiII, Interamericana S.A. 5ta edición.

- Organización de las Naciones Unidas para la Educación, la Ciencia y la Cultura (UNESCO), (1976). "Actas de la Conferencia General" 19a reunión. Volumen 1, Resoluciones. Disponible en: http://unesdoc.unesco.org/images/0011/001140/114038s.pdf\#page=137

- Piumetto, Mario (2007). Conceptos básicos de Sistemas de Información Geográfica. Lincoln Institute of Land Policy, Educación a Distancia, Programa para América Latina. 